\title{
Synthesis and Properties of the Aromatic Polyamides Containing the 2,4'-Biphenyldiyl Structure
}

\author{
Fumihiko Akutsu*, Norihisa Sugiyama, Nobuyuki Ando, \\ Yoshio Kasashima, Mari INOKI, and KiYoshi Naruchi \\ Department of Applied Chemistry, Faculty of Engineering, Chiba University, \\ Yayoi-cho 1-33, Inage-ku, Chiba-shi 263, Japan
}

(Received April 24, 1995)

\begin{abstract}
Novel aromatic polyamides were synthesized from 2,4'-biphenyldiamine by low-temperature solution polycondensation. The polyamides were soluble in pyridine, $m$-cresol, $N, N$-dimethylacetamide, 1-methyl-2-pyrrolidone, hexamethylphosphoric triamide, $N, N$-dimethylformamide, dimethylsulfoxide, and conc. $\mathrm{H}_{2} \mathrm{SO}_{4}$. The glass-transition temperatures $\left(T_{\mathrm{g}} \mathrm{s}\right)$ were found in the $248-284^{\circ} \mathrm{C}$ range. The temperatures at $5 \%$ weight loss in nitrogen atmosphere $\left(T_{\mathrm{d}} \mathrm{s}\right)$ were $435-459^{\circ} \mathrm{C}$, and residual weights at $600^{\circ} \mathrm{C}$ were $43-56 \%$. The introduction of $2,4^{\prime}$-biphenyldiyl structure to the backbones of aromatic polyamides improves solubility without lowering high thermal stability. In addition, brominated aromatic polyamides were synthesized from $N, N^{\prime}$-bis(trimethylsilyl)-5-bromo-2,4'-biphenyldiamine, and their properties were compared with those of none-brominated polyamides. The brominated aromatic polyamides indicated higher solubility, though their $T_{\mathrm{g}} \mathrm{s}$ were as high as those of none-brominated polyamides. As concerns thermal decomposition behavior, the introduction of a bromo-group to the structures of aromatic polyamides lowered $T_{\mathrm{d}} \mathrm{s}$, but heightened residual weight.
\end{abstract}

KEY WORDS 2,4'-Biphenyldiamine / Aromatic Polyamide / Solubility /

Thermal Property / 5-Bromo-2,4'-biphenyldiamine / $N, N^{\prime}$-Bis(trimethylsilyl)-

5-bromo-2,4'-biphenyldiamine /

Wholly aromatic polyamides are well known as high-performance polymers. Their rigid structures induce not only high thermal stability, but poor solubility in many organic solvents ${ }^{1}$ with consequently low processability. Thus, it is necessary to improve the solubility of aromatic polyamides without lowering high thermal resistance in order to apply to industry. It was found that the introduction of rigid and zigzag structures, e.g., 2,3-quinoxalinediyl, ${ }^{2-5}$ 1,2,4-triazine-5,6-diyl, ${ }^{6,7}$ 2-phenyl-4,5-imidazolediyl, ${ }^{8}$ and $4,4^{\prime \prime}$-o-terphenyldiyl ${ }^{9,10}$ structures, to the main chains of polyamides improved solubility with keeping high thermal stability, and the effect produced by heterocycles on the improvement of the solubility is larger than that by $4,44^{\prime \prime}-o$-terphenyldiyl structure. Glass-transition temperatures $\left(T_{\mathrm{g}} \mathrm{s}\right)$ of the polyamide having the heterocycles were higher than that of the corresponding polyamide containing the $4,44^{\prime \prime}-o$-terphenyldiyl structure. The introduction of a polar substituent to the zigzag structures of aromatic polyamides may thus be effective for improving solubility and heightening $T_{\mathrm{g}}$.

This study investigates the synthesis and properties of novel aromatic polyamides introduced rigid and zigzag 2,4'-biphenyldiyl structure to backbones in order to improve solubility without lowering highly thermal properties. Novel aromatic polyamides having 5-bromo-2,4'-biphenyldiyl structure were

\footnotetext{
* To whom correspondence should be addressed.
} 
studied. Kuze et al. reported that the introduction of the chloro-group as a side substituent to the structures of poly $(m$-phenyleneisophthalamide) and poly ( $m$-phenyleneterephthalamide) improves solubility and lowers $T_{\mathrm{g}} \mathrm{s} .{ }^{11}$ The main chains of these polyamides were linear, but those of polyamides containing 2,4'-biphenyldiyl structure were zigzag. Effects on the solubility and $T_{\mathrm{g}}$ of the zigzag polyamides produced by the introduction of the halogeno-group as the polar substituent have not been investigated. Aromatic polyimide prepared from the diamine 1 with $3,3^{\prime}, 4,4^{\prime}$ benzophenonetetracarboxylic dianhydride has been reported ${ }^{11}$ by Bell et al., but there has been no reports on polyamide containing $2,4^{\prime}$ biphenyldiyl structure yet.

\section{RESULTS AND DISCUSSION}

\section{Monomer and Polymer Synthesis}

2,4'-Biphenyldiamine (diphenyline) 1 was obtained by the reduction of 2-amino- $4^{\prime}$ nitrobiphenyl. ${ }^{13}$ The synthesis of 5-bromo-2,4'biphenyldiamine 4 was attempted according to the method using benzidine-rearregement from 4-bromoazobenzene ${ }^{14}$ reported Jacobson et al., but the attempt was unsuccessful due to reduction of the bromo-group accompanying the reduction of the azobenzene. There have not been any other reports on brominated diamine 4. Diamine 4 was thus synthesized by reduction of 2- amino-5-bromo-4'-nitrobiphenyl 8 using a $\mathrm{Fe}-\mathrm{HCl}$ system. The boiling point of diamine 4 was so high that the crude products could not be purified by distillation under reduced pressure. Thus, acetylation was carried out. Diacetamide 9 was purified by recrystallization, and then hydrolyzed. The hydrolyzate, a clear yellow oil, was identified as diamine 4 by spectroscopic data as well as by elemental analysis.

Polyamides 3 were prepared by low-temperature solution polycondensation ${ }^{15}$ of diamine 1 with several aromatic dicarbonyl dichlorides 2. Methyloxirane was used as the hydrogen chloride acceptor. The results are shown in Table I. All polycondensations proceeded to homogeny. The IR spectra of the polymers showed characteristic amide absorptions near 1660 and $1520 \mathrm{~cm}^{-1}$. All polyamides were obtained in quantitative yields. The inherent viscosities of polyamides 3 were in the range of $0.42-0.72 \mathrm{dlg}^{-1}$.

Polyamide 6a was synthesized from diamine 4 by a similar procedure, but the inherent viscosity of the produced polyamide was a low $0.13 \mathrm{dl} \mathrm{g}^{-1}$. It was assumed that a slight impurity contained by diamine 4 influenced the degree of polymerization. Therefore, $N$-trimethylsilylation ${ }^{16}$ of diamine 4 was performed because the boiling point was lowered and the reactivity of diamine was heightened. After the $N$-silylated product was distilled under reduced pressure, the distillate was identified as $N, N^{\prime}$ bis(trimethylsilyl)-5-bromo-2,4'-biphenyldiamine 5 by spectroscopic data and elemental analysis. Polyamides 6 were prepared by lowtemperature solution polycondensation ${ }^{17,18}$ of $N$-silylated diamine $\mathbf{5}$ with several aromatic dicarbonyl dichlorides 2 . The results are summarized in Table I. The inherent viscosities of polyamides 6 were improved, but were not high, ranging from 0.20 to $0.26 \mathrm{dlg}^{-1}$. It was

Table I. Data of prepared polyamides

\begin{tabular}{|c|c|c|c|c|}
\hline Polymer & Diamines & $\frac{\text { Yield }}{\%}$ & $\frac{\eta_{\mathrm{inh}}^{\mathrm{a}}}{\mathrm{dl} \mathrm{g}^{-1}}$ & Color \\
\hline $3 \mathbf{a}$ & 1 & 91.8 & 0.72 & White \\
\hline $3 \mathbf{b}$ & 1 & 98.6 & 0.49 & White \\
\hline $3 c$ & 1 & 99.5 & 0.59 & White \\
\hline 3d & 1 & 99.1 & 0.41 & White \\
\hline $3 e$ & 1 & 90.7 & 0.45 & White \\
\hline $6 \mathbf{a}$ & 4 & 97.1 & 0.13 & White \\
\hline $6 \mathbf{a}$ & 5 & 99.3 & 0.22 & White \\
\hline $\mathbf{6 b}$ & 5 & 96.1 & 0.22 & White \\
\hline $6 c$ & 5 & 100.2 & 0.21 & White \\
\hline 6d & 5 & 99.9 & 0.26 & White \\
\hline $6 e$ & 5 & 99.6 & 0.20 & White \\
\hline
\end{tabular}

${ }^{a}$ Inherent viscosity measured in conc. sulfuric acid $\left(0.50 \mathrm{~g} \mathrm{dl}^{-1}\right)$ at $30^{\circ} \mathrm{C}$. 
considered that the low reactivity of the formed oligomers by steric hindrance contributed to the low inherent viscosities of polyamides 6 .

\section{Thermal Properties of Polyamides}

$T_{\mathrm{g}} \mathrm{s}$ were determined by differential scanning calorimetry (DSC). The temperatures at $5 \%$ weight loss $\left(T_{\mathrm{d}} \mathrm{s}\right)$ and weight residues at $600^{\circ} \mathrm{C}$ were determined by thermogravimetry (TG). Thermal behavior of polyamides are summarized in Table II. $T_{\mathrm{g}}$ of polyamide $\mathbf{3 d}$ and that of $6 \mathbf{d}$ were not observed by DSC. $T_{\mathrm{g}} \mathrm{s}$ of polyamides 3 were found in the range of 248$284^{\circ} \mathrm{C}$, and those of polyamides 6 ranged from 249 to $288^{\circ} \mathrm{C}$. It was expected that $T_{\mathrm{g}} \mathrm{s}$ of polyamides 6 were lower due to their low inherent viscosities. However, $T_{\mathrm{g}} \mathrm{s}$ of $\mathbf{6}$ are as high as those of $\mathbf{3}$. This indicated that polyamides 6 have enough inherent viscosities to investigate their physical and chemical properties. The results of those $T_{\mathrm{g}} \mathrm{s}$ were attributed to a bulkiness of the bromo-group as the side substituent and to the dipole-dipole interactions between the polymer chains by the polarity of the bromo-group.

$T_{\mathrm{d}} \mathrm{s}$ of polyamides 3 were found in the 435 $459^{\circ} \mathrm{C}$ range. $T_{\mathrm{d}} \mathrm{s}$ of polyamides 6 ranged from 364 to $403^{\circ} \mathrm{C}$, which were lower than those of corresponding polyamides 3 . The weight residues at $600^{\circ} \mathrm{C}$ of polyamides 3 were in the $43-56 \%$ range. However, those of polyamides 6 ranged between 59 and $71 \%$, which were higher than those of corresponding polyamides 3. Figure 1 shows the typical TG-curves of polyamide 3d and corresponding brominated polyamide $\mathbf{6 d}$ in nitrogen atmosphere. $T_{\mathrm{d}}$ of $\mathbf{6 d}$ was $403^{\circ} \mathrm{C}$, which was $49^{\circ}$-lower than that of 3d. On the contrary, the residual weight at $600^{\circ} \mathrm{C}$ of $6 \mathrm{~d}$ was high; the value was $71 \%$, which was $15 \%$ higher than that of $\mathbf{3 d}$. In addition, while the thermal degradation of polyamide $\mathbf{3 d}$ occurred in one step, 6d pyrolyzed in two steps; the first drop was $11 \%$ decrease at the 384 $430^{\circ} \mathrm{C}$ range. It was considered that the first decrease of the pyrolysis of $\mathbf{6 d}$ corresponded to the scission of the $\mathrm{C}-\mathrm{Br}$ bond. The thermal
Table II. Thermal properties of polyamides

\begin{tabular}{|c|c|c|c|}
\hline Polymer & $\frac{T_{\mathrm{g}}^{\mathrm{a}}}{{ }^{\circ} \mathrm{C}}$ & $\frac{T_{\mathrm{d}}^{\mathrm{b}}}{{ }^{\circ} \mathrm{C}}$ & $\begin{array}{l}\text { White residue } \\
\text { at } 600^{\circ} \mathrm{C} / \%^{\mathrm{c}}\end{array}$ \\
\hline $3 \mathbf{a}$ & 248 & 435 & 43 \\
\hline $\mathbf{3 b}$ & 275 & 445 & 49 \\
\hline $3 c$ & 251 & 442 & 47 \\
\hline 3d & ${ }^{d}$ & 452 & 56 \\
\hline $3 e$ & 284 & 459 & 56 \\
\hline $6 a$ & 253 & 379 & 69 \\
\hline $\mathbf{6 b}$ & 285 & 383 & 63 \\
\hline 6c & 249 & 380 & 69 \\
\hline 6d & $\underbrace{d}$ & 403 & 71 \\
\hline $6 e$ & 288 & 364 & 59 \\
\hline
\end{tabular}

${ }^{\text {a }}$ Measured by differential scanning calorimetry (DSC) (heating rate $10 \mathrm{k} \mathrm{min}^{-1}$ in nitrogen atmosphere). ${ }^{\mathrm{b}} \mathrm{Tem}-$ perature at $5 \%$ weight loss was determined by thermogravimetry (TG) (heating rate $10 \mathrm{~K} \mathrm{~min}^{-1}$ in nitrogen atmosphere). ${ }^{\mathrm{c}}$ Determined by TG. ${ }^{\mathrm{d}}$ Not observed by DSC.

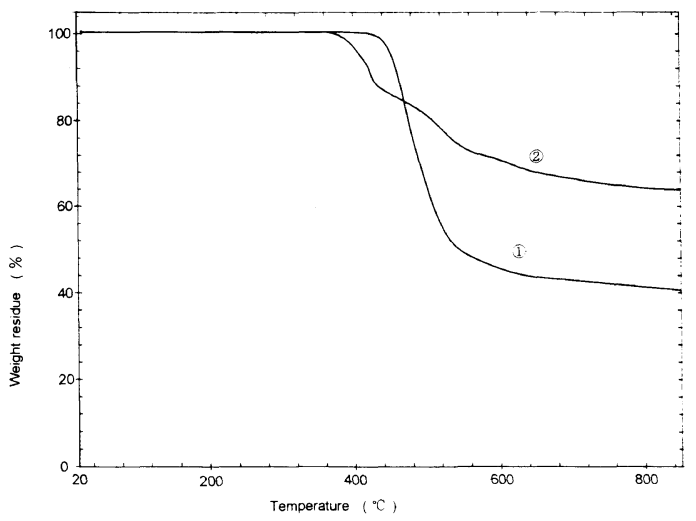

Figure 1. TG curves at a heating rate of $10 \mathrm{~K} \mathrm{~min}^{-1}$ in nitrogen atmosphere for polyamide 3d (1) and for brominated polyamide $6 \mathbf{d}$ ( (2)).

degradation of aromatic polyamides proceeds crosslinking and condensation reaction with elimination of gases such as water, carbon monoxide, carbon dioxide, hydrogen cyanide, hydrogen, and methane. ${ }^{19,20}$ Nara et al. reported that, in the thermal degradation of the tetrabrominated epoxy resin, hydrogen bromide produced by the initial thermal decomposition promotes crosslinking or con- 
densation reaction of residual polymer. ${ }^{21}$ Therefore, it is suggested that the pyrolysis of 6d causes the cleavage of the $\mathrm{C}-\mathrm{Br}$ bond initially, and hydrogen bromide formed promotes crosslinking or condensation reaction of the residual polymer.

\section{Solubility of Polyamides}

Solubilities in several organic solvents are summarized in Table III. Polyamides 3 showed high solubility. In particular, polyamide $\mathbf{3 a}$ was soluble in conc. $\mathrm{H}_{2} \mathrm{SO}_{4}$, dimethylsulfoxide (DMSO), $N, N$-dimethylformamide (DMF), hexamethylphosphoric triamide (HMPA), 1methyl-2-pyrrolidone (NMP), N,N-dimethylacetamide (DMAc), $m$-cresol, and pyridine. Polyamides 6 exhibited higher solubilities than polyamides 3 ; $6 \mathbf{a}, \mathbf{6 b}, \mathbf{6 c}$, and $6 \mathbf{6}$ were soluble in conc. $\mathrm{H}_{2} \mathrm{SO}_{4}$, DMSO, DMF, HMPA, NMP, DMAc, $m$-cresol, pyridine, and cyclohexanone. Polyamides 6 indicated higher solubilities than polyamides 3 though $T_{\mathrm{g}} \mathrm{s}$ of $\mathbf{6}$ were as high as those of 3 . This was attributed to the effect of the introduction of a polar and bulky bromo-group into the structures of polyamides.

\section{Conclusion}

It is concluded that the introduction of $2,4^{\prime}$-biphenyldiyl structure, which is rigid and zigzag, to the backbones of aromatic polyamides improves the solubility without lowering high thermal stability, and that the introduction of a bromo-group to the structures of aromatic polyamides containing 2,4'-biphenyldiyl structure improves solubility keeping high $T_{\mathrm{g}} \mathrm{s}$, but influences thermal decomposition behavior, lowers $T_{\mathrm{d}} \mathrm{s}$, and heightens residual weight.

\section{EXPERIMENTAL}

\section{Material}

2-Amino-4'-nitrobiphenyl was prepared by the nitration $^{13}$ of 2-aminobiphenyl (Tokyo Kasei Kogyo Co.), and purified by recrystallization from methanol/water mixture (methanol: water $=1: 20$ in volume). $\mathrm{mp}$ $157.0-159.0^{\circ} \mathrm{C} \quad$ (lit. $^{13} 156.0-158.5^{\circ} \mathrm{C}$ ). 2Amino-5-bromobiphenyl 7 was synthesized from 2-aminobiphenyl according to the meth$\mathrm{od}^{22}$ reported by Scarborough et al. $\mathrm{mp}$ $57.0-58.0^{\circ} \mathrm{C}$ (lit. $^{22} 57.5^{\circ} \mathrm{C}$ ).

\section{2,4'-Biphenyldiamine (1)}

Diamine 1 was obtained by the reduction of 2-amino-4'-nitrobiphenyl using a $\mathrm{SnCl}_{2}-\mathrm{HCl}$ system. The reduction products were purified by distillation twice under reduced pressure

Table III. Polyamide solubilities ${ }^{\mathrm{a}}$

\begin{tabular}{|c|c|c|c|c|c|c|c|c|c|}
\hline Polymer & $\mathrm{CHO}$ & Py & $m$-Cre & DMAc & NMP & HMPA & DMF & DMSO & $\mathrm{H}_{2} \mathrm{SO}_{4}$ \\
\hline $3 \mathbf{a}$ & $( \pm)$ & + & + & + & + & $(+)$ & + & + & + \\
\hline $\mathbf{3 b}$ & - & \pm & + & + & + & $(+)$ & SW & + & + \\
\hline $3 c$ & $( \pm)$ & + & + & + & + & $(+)$ & \pm & + & + \\
\hline 3d & - & - & $( \pm)$ & $( \pm)$ & + & + & $( \pm)$ & + & + \\
\hline $3 e$ & $( \pm)$ & \pm & \pm & \pm & + & $(+)$ & - & \pm & + \\
\hline $6 a$ & $(+)$ & + & + & + & + & + & + & + & + \\
\hline $\mathbf{6 b}$ & $(+)$ & + & + & + & + & + & + & + & + \\
\hline $6 c$ & $(+)$ & + & + & + & + & $(+)$ & + & + & + \\
\hline 6d & $( \pm)$ & $( \pm)$ & + & + & + & + & + & + & + \\
\hline $6 e$ & + & + & + & + & + & + & + & + & + \\
\hline
\end{tabular}

${ }^{a}$ Measured at $2.0 \%(\mathrm{w} / \mathrm{v})$. Data in parentheses were obtained during heating. CHO, Cyclohexanone; Py, pyridine; $m$-Cre, $m$-cresol; DMAc, $N, N$-dimethylacetamide; NMP, 1-methyl-2-pyrrolidone; HMPA, hexamethylphosphoric triamide; DMF, $N, N$-dimethylformamide; DMSO, dimethylsulfoxide.

+ , Soluble; \pm , partially soluble; - , insoluble; SW, swelling. 

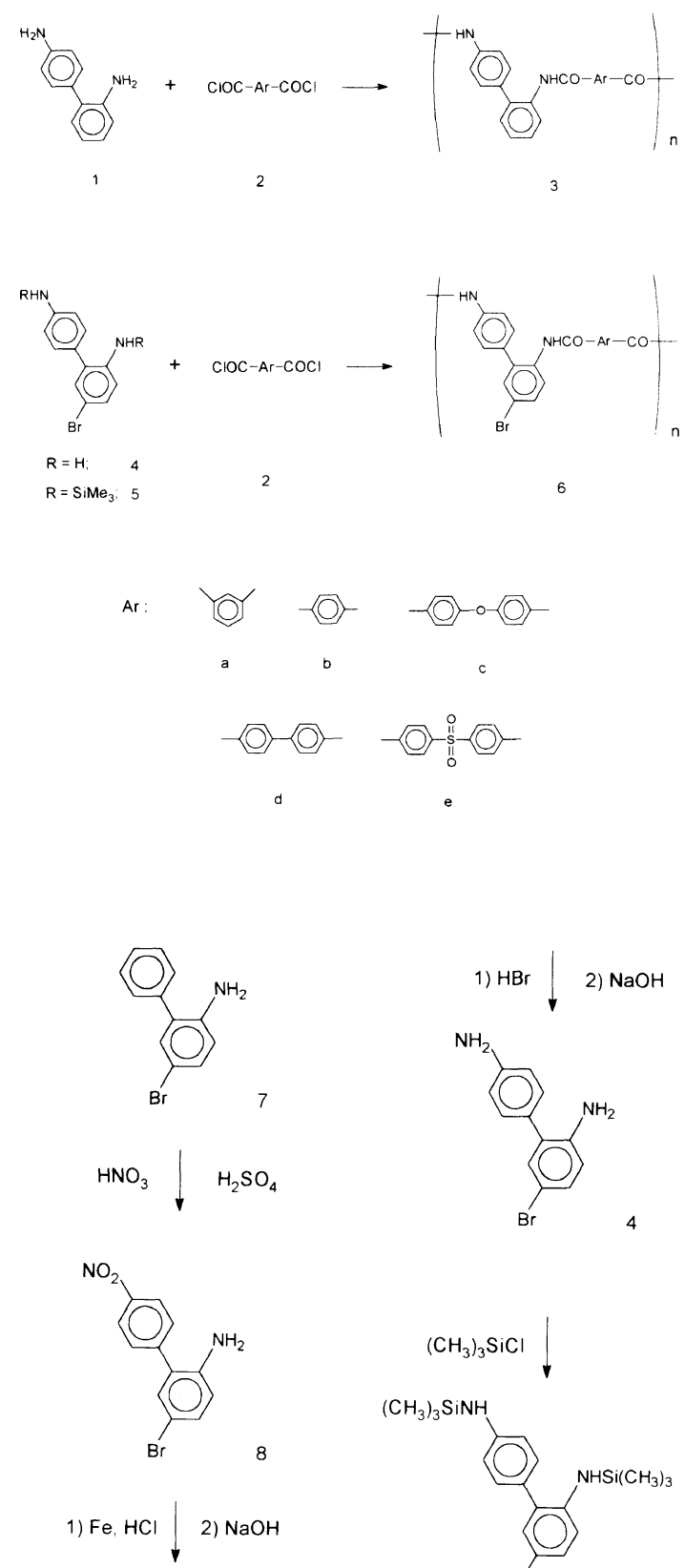

$$
\left(\mathrm{CH}_{3} \mathrm{CO}\right)_{2} \mathrm{O}
$$
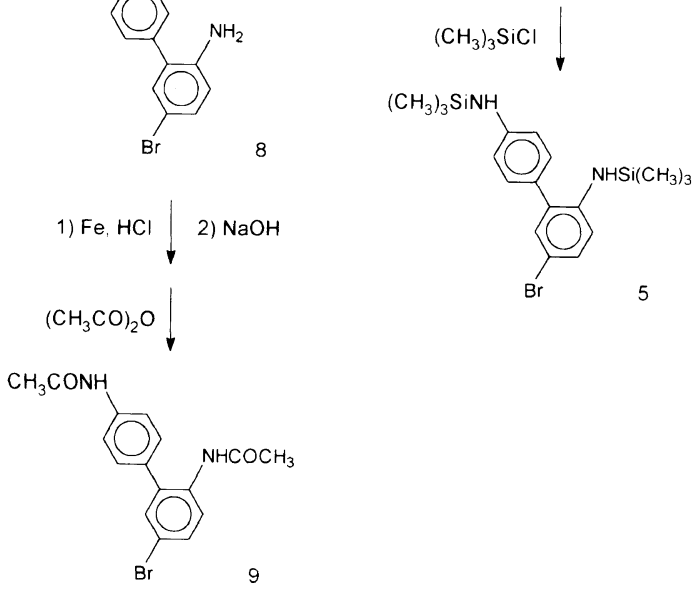

with zinc dust (bp $161.0-163.0^{\circ} \mathrm{C} / 1 \mathrm{mmHg}$ ). The distillate was a clear oil, but slowly crystallized. mp $56.0-57.0^{\circ} \mathrm{C}$ (lit. ${ }^{11,22} 54.0-$ $54.5^{\circ} \mathrm{C}$ ), pale yellow crystals.

IR ( $\mathrm{KBr}$ disk) 3456 and $3384 \mathrm{~cm}^{-1}(\mathrm{~N}-\mathrm{H})$.

${ }^{13} \mathrm{C}-\mathrm{NMR}\left(\mathrm{CDCl}_{3}, 100 \mathrm{MHz}, \mathrm{ppm}\right) 115.3$ $\left(\mathrm{C}_{3^{\prime}}, \mathrm{C}_{5^{\prime}}\right), 115.4\left(\mathrm{C}_{3}\right), 118.6\left(\mathrm{C}_{5}\right), 127.8\left(\mathrm{C}_{1}\right)$, $127.9\left(\mathrm{C}_{4}\right), 129.4\left(\mathrm{C}_{1^{\prime}}\right), 130.0\left(\mathrm{C}_{2^{\prime}}, \mathrm{C}_{6^{\prime}}\right), 130.4$ $\left(\mathrm{C}_{6}\right), 143.8\left(\mathrm{C}_{2}\right)$, and $145.5\left(\mathrm{C}_{4}\right)$.

Analysis. Calcd for $\mathrm{C}_{12} \mathrm{H}_{12} \mathrm{~N}_{2}$ (184.2): C, $78.23 \% ; \mathrm{H}, 6.56 \% ; \mathrm{N}, 15.20 \%$. Found : C, $78.32 \% ; \mathrm{H}, 6.51 \% ; \mathrm{N}, 15.34 \%$.

\section{2-Amino-5-bromo-4'-nitrobiphenyl (8)}

In a 50-ml four-necked flask equipped with a reflux condenser and thermometer were placed $4.82 \mathrm{~g}$ of 7, $29.0 \mathrm{ml}$ of conc. sulfuric acid, and a magnetic stirrer bar. The mixture was stirred to dissolve the solids, cooled to $0^{\circ} \mathrm{C}$, and a mixture of $2.15 \mathrm{ml}$ conc. sulfuric acid and $0.81 \mathrm{ml}$ fuming nitric acid was added dropwise for $50 \mathrm{~min}$. The mixture was stirred below $0^{\circ} \mathrm{C}$ for $1 \mathrm{~h}$, poured into crushed ice, and neutralized with aqueous $\mathrm{NaOH}$ solution. The precipitates were filtrated, washed with water, and dried under reduced pressure at $60^{\circ} \mathrm{C}$. Crude products were recrystallized from ethanol. Yield $59.8 \%$. mp $149.4^{\circ} \mathrm{C}$ (DTA).

IR (KBr disk) $3476,3384,1624 \mathrm{~cm}^{-1}(\mathrm{~N}-\mathrm{H})$, 1512 and $1350 \mathrm{~cm}^{-1}(\mathrm{~N}-\mathrm{O})$.

Analysis. Calcd for $\mathrm{C}_{12} \mathrm{H}_{9} \mathrm{~N}_{2} \mathrm{O}_{2} \mathrm{Br}$ (293.1): C, $49.17 \%$; H, 3.09\%; N, 9.56\%. Found: C, $49.10 \%$; H, $2.96 \%$; N, $9.50 \%$.

\section{5-Bromo-2,4'-diacetamidebiphenyl (9)}

In a 50 -ml four-necked flask equipped with a reflux condenser and thermometer were placed $10.0 \mathrm{~g}$ of $8,37.2 \mathrm{ml}$ of methanol, $19.0 \mathrm{ml}$ of hydrochloric acid, and a magnetic stirrer bar. Powdered iron $(5.8 \mathrm{~g})$ was added for $50 \mathrm{~min}$. The mixture was refluxed for $3 \mathrm{~h}$, and poured into $100 \mathrm{ml} 50 \%$ aqueous solution of citric acid. The aqueous solution was made basic to litmus with $10 \% \mathrm{NaOH}$ aqueous solution. The precipitates were filtered and washed with ether three times. The filtrate was 
extracted with three portions of ether. The combined ether layer was dried with anhydrous sodium sulfate over night. Ether was removed by evaporation and dark black oil was obtained.

The oil was dissolved in $11.5 \mathrm{ml}$ benzene, and poured into a Erlenmeyer-flask. After acetic anhydride $(5.9 \mathrm{ml})$ was added dropwise, the reaction mixture was allowed to stand over night. The precipitates were filtrated, washed with water, and dried under reduced pressure at $60^{\circ} \mathrm{C}$ over night. Crude products were purified by recrystallization from ethanol. Yield $60.7 \%$. mp $230.1^{\circ} \mathrm{C}$ (DTA).

IR ( $\mathrm{KBr}$ disk) $3280 \mathrm{~cm}^{-1}(\mathrm{~N}-\mathrm{H}), 1656$ and $1528 \mathrm{~cm}^{-1}$ (amides -I, -II).

Analysis. Calcd for $\mathrm{C}_{16} \mathrm{H}_{15} \mathrm{~N}_{2} \mathrm{O}_{2} \mathrm{Br}$ (347.2): C, $55.35 \%$; H, 4.35\%; N, 8.07\%. Found: C, $55.21 \%$; H, $4.19 \%$; N, $8.11 \%$.

\section{5-Bromo-2,4'-biphenyldiamine (4)}

In a $300-\mathrm{ml}$ flask equipped with a reflux condenser were placed $3.02 \mathrm{~g}$ of $9,60.0 \mathrm{ml}$ of ethanol, and a magnetic stirrer bar. The mixture was stirred on heating to dissolve the solids. Then, $140 \mathrm{ml}$ hydrobromic acid was added. The reaction mixture was refluxed for $10 \mathrm{~h}$, cooled to room temperature. After removal of ethanol with an evaporator, aqueous $\mathrm{NaOH}$ solution was added to the residue. The aqueous solution was extracted with three portions of ether and the combined ether-layer was dried with anhydrous sodium sulfate over night. A pale yellow clear oil was obtained by removal of ether with an evaporator. The oil was dried under reduced pressure at $60^{\circ} \mathrm{C}$ over night. Yield $97.4 \%$.

IR ( $\mathrm{KBr}$ neat) 3476,3396 , and $1622 \mathrm{~cm}^{-1}$ $(\mathrm{N}-\mathrm{H})$.

${ }^{13} \mathrm{C}-\mathrm{NMR}\left(\mathrm{CDCl}_{3}, 125 \mathrm{MHz}, \mathrm{ppm}\right) 110.1$ $\left(\mathrm{C}_{5}\right), 115.3\left(\mathrm{C}_{3^{\prime}}, \mathrm{C}_{5^{\prime}}\right), 116.9\left(\mathrm{C}_{3}\right), 128.1\left(\mathrm{C}_{1^{\prime}}\right)$, $129.7\left(\mathrm{C}_{1}\right), 129.9\left(\mathrm{C}_{2^{\prime}}, \mathrm{C}_{6}\right), 130.4\left(\mathrm{C}_{6}\right), 132.7$ $\left(\mathrm{C}_{4}\right), 142.8\left(\mathrm{C}_{2}\right)$, and $145.9\left(\mathrm{C}_{4}\right)$.

Analysis. Calcd for $\mathrm{C}_{12} \mathrm{H}_{11} \mathrm{~N}_{2} \mathrm{Br}$ (263.1): C, $54.77 \%$; H, 4.21\%; N, 10.65\%. Found: C, $54.94 \% ; \mathrm{H}, 4.13 \% ; \mathrm{N}, 10.36 \%$.
$N, N^{\prime}$-Bis(trimethylsilyl)-5-bromo-2,4'-biphenyldiamine (5)

In a $10-\mathrm{ml}$ four-necked flask equipped with a reflux condenser having a calcium chloride tube, nitrogen gas inlet, thermometer, and dropping funnel were placed $9.75 \mathrm{ml}$ of triethylamine, $5.97 \mathrm{~g}$ of diamine $4,42.6 \mathrm{ml}$ of dry benzene and a magnetic stirrer bar. The mixture was stirred to dissolve the solids and trimethylsilyl chloride $(6.70 \mathrm{ml})$ was added dropwise for $1 \mathrm{~h}$. The reaction mixture was stirred at $60^{\circ} \mathrm{C}$ for $2 \mathrm{~h}$, and refluxed for $25 \mathrm{~h}$, and cooled to room temperature. Triethylamine hydrochloride that formed was removed by filtration with a G3 glass filter, and benzene was removed by distillation. The obtained products were purified by distillation under reduced pressure $\left(169.0-169.2^{\circ} \mathrm{C} / 1.8 \mathrm{mmHg}\right)$. Yield 55.7\% (pale yellow clear oil).

IR (neat): $3392,1518 \mathrm{~cm}^{-1}(\mathrm{~N}-\mathrm{H})$, and 1254 $\mathrm{cm}^{-1}(\mathrm{Si}-\mathrm{C})$.

Analysis. Calcd for $\mathrm{C}_{18} \mathrm{H}_{27} \mathrm{~N}_{2} \mathrm{BrSi}_{2}$ (407.5): C, $53.05 \%$; H, 6.68\%; N, 6.87\%. Found: C, $52.82 \% ; \mathrm{H}, 6.58 \% ; \mathrm{N}, 6.99 \%$.

\section{Aromatic Dicarbonyl Dichlorides (2)}

Aromatic dicarbonyl dichlorides were synthesized from the corresponding aromatic dicarboxylic acids with thionyl chloride and DMF. 4,4'-Oxydibenzoic acid was prepared by the oxidation ${ }^{23}$ of $4,4^{\prime}$-oxyditoluene obtained from Tokyo Kasei Kogyo Co., with potassium permangate in aqueous pyridine. 4,4'-Biphenyldicarboxylic acid was obtained from Tokyo Kasei Kogyo Co. and used as received. 4,4'Sulfonyldibenzoic acid was obtained from New Japan Chemical Co., Ltd. and used as received. Isophthaloyl dichloride (2a) was recrystallized from dry ligroin. Terephthaloyl dichloride (2b) and 4,4'-oxydibenzoyl dichloride (2c) were recrystallized from dry $n$-hexane. 4,4'-Biphenyldicarbonyl dichloride (2d) and 4,4'-sulfonyldibenzoyl dichloride (2e) were recrystallized from dry benzene. 
Low-Temperature Solution Polycondensation of Diamines with Aromatic Dicarbonyl Dichlorides

A typical procedure is as follows. In a $10-\mathrm{ml}$ reaction tube equipped with a nitrogen gas inlet having a calcium chloride tube were placed $0.1500 \mathrm{~g}$ lithium chloride, $0.1842 \mathrm{~g}$ diamine 1 , and $2.0 \mathrm{ml} \mathrm{NMP.} \mathrm{The} \mathrm{mixture} \mathrm{was} \mathrm{stirred} \mathrm{to}$ dissolve the solids, cooled to $-18^{\circ} \mathrm{C}$, and $0.2032 \mathrm{~g}$ of isophthaloyl dichloride and 0.78 $\mathrm{ml}$ of methyloxirane were added. The mixture was stirred at $-18^{\circ} \mathrm{C}$ for $2 \mathrm{~h}$, and at room temperature for $5 \mathrm{~h}$. The reaction mixture was poured into aqueous methanol $(\mathrm{MeOH}$ : $\mathrm{H}_{2} \mathrm{O}=1: 1$ in volume), and the precipitates were collected with a glass filter, washed with hot methanol and dried under reduced pressure at $60^{\circ} \mathrm{C}$. Yield $91.8 \%$.

$\eta_{\text {inh }}=0.72 \mathrm{dlg}^{-1}\left(0.5 \mathrm{~g} \mathrm{dl}^{-1}\right.$ conc. $\mathrm{H}_{2} \mathrm{SO}_{4}$ at $\left.30^{\circ} \mathrm{C}\right)$. IR ( $\mathrm{KBr}$ disk) 1656 and $1526 \mathrm{~cm}^{-1}$ (amides I, II).

Analysis. Calcd for $\left(\mathrm{C}_{20} \mathrm{H}_{14} \mathrm{~N}_{2} \mathrm{O}_{4}\right)_{n}(314.3)_{n}$ : C, $76.42 \%$; H, 4.49\%; N, $8.91 \%$. Found: C, $74.06 \% ; \mathrm{H}, 4.37 \%$; N, $8.61 \%$.

Other polyamides were synthesized by a similar procedure.

\section{Low-Temperature Solution Polycondensation of \\ $N$-Silylated Diamine 5 with Aromatic Di- carbonyl Dichlorides}

A typical procedure is as follows. In a $10-\mathrm{ml}$ reaction tube equipped with a nitrogen gas inlet having a calcium chloride tube were placed $0.4273 \mathrm{~g}$ of $N$-silylated diamine 5 and $1.5 \mathrm{ml}$ of NMP. The mixture was stirred to dissolve the solids, cooled to $-18^{\circ} \mathrm{C}$, and then $0.2927 \mathrm{~g}$ of $2 \mathrm{~d}$ and $0.5 \mathrm{ml}$ of NMP were added. The mixture was stirred at $-18^{\circ} \mathrm{C}$ for $2 \mathrm{~h}$, and at room temperature for $5 \mathrm{~h}$. The reaction mixture was poured into aqueous methanol $(\mathrm{MeOH}$ : $\mathrm{H}_{2} \mathrm{O}=1: 1$ in volume). The precipitates were collected with a glass filter, washed with hot methanol and dried under reduced pressure at $60^{\circ} \mathrm{C}$. Yield $99.9 \%$.

$$
\eta_{\text {inh }}=0.26 \mathrm{dl} \mathrm{g}^{-1}\left(0.5 \mathrm{~g} \mathrm{dl}^{-1} \text { conc. } \mathrm{H}_{2} \mathrm{SO}_{4}\right. \text { at }
$$
$30^{\circ} \mathrm{C}$ ). IR (KBr) 1660 and $1516 \mathrm{~cm}^{-1}$ (amides
I, II).

Analysis. Calcd for $\left(\mathrm{C}_{26} \mathrm{H}_{18} \mathrm{~N}_{2} \mathrm{O}_{2} \mathrm{Br}\right)_{n}$ (469.3) $)_{n}$ C, 66.54\%; H, 3.65\%; N, 5.97\%. Found: C, $65.11 \%$; H, 3.49\%; N, 5.89\%.

Other polyamides were synthesized by similar procedures.

\section{Measurements}

$T_{\mathrm{g}} \mathrm{s}$ were determined by DSC (Rigaku Denki 8230D). $\quad T_{\mathrm{d}} \mathrm{s}$ and residual weights were determined by TG (Mac Science TG-DTA 2000). IR spectra were recorded on a Hitachi 270-30 spectrophotometer. ${ }^{13} \mathrm{C}$ NMR spectra were obtained with FT-NMR spectrometer (JEOL JNM-GSX400 or JNM-GSX500).

Acknowledgments. We thank the Chemical Analysis Center, Chiba University, for carrying out the elemental analyses and recording the NMR spectra. We are indebted to New Japan Chemical Co., Ltd., for providing the $4,4^{\prime}$ sulfonyldibenzoic acid.

\section{REFERENCES}

1. P. E. Cassidy, "Thermally Stable Polymers," Dekker, New York, N.Y., 1980.

2. F. Akutsu, H. Hirata, H. Hayashi, M. Miura, and K. Nagakubo, Makromol. Chem., Rapid Commun., 6, 215 (1985).

3. F. Akutsu, H. Hayashi, M. Miura, and K. Nagakubo, Makromol. Chem., Rapid Commun., 6, 407 (1985).

4. F. Akutsu, H. Hayashi, M. Miura, and K. Nagakubo, Makromol. Chem., Rapid Commun., 6, 475 (1985).

5. F. Akutsu, K. Matsuo, N. Naruchi, and M. Miura, Polym. Commun., 30, 182 (1987).

6. F. Akutsu, H. Takeyama, M. Miura, and K. Nagakubo, Makromol. Chem., 186, 483 (1985).

7. F. Akutsu, A. Suzuki, F. Saitoh, K. Naruchi, M. Miura, and K. Nagakubo, Makromol. Chem., 188, 1253 (1987).

8. F. Akutsu, T. Kataoka, K. Naruchi, M. Miura, and K. Nagakubo, Polymer, 28, 1787 (1987).

9. Y. Kasashima, K. Yamamoto, N. Ando, F. Akutsu, K. Naruchi, and M. Miura, Polym. J., 26, 1298 (1994).

10. Y. Kasashima, H. Kumada, K. Yamamoto, F. Akutsu, K. Naruchi, and M. Miura, Polymer, 36, 645 (1995).

11. K. Kuze and S. Miwa, Kogyo Kagaku Zasshi, 71, 443 (1968); Chem. Abstr., 69, 36507j (1968). 
12. V. L. Bell, B. L. Stump, and H. Gager, J. Polym. Sci., Polym. Chem. Ed., 14, 2275 (1976).

13. G. D. Mendenhall and P. A. S. Smith, Org. Syn., 46, 85 (1966).

14. P. Jacobson and R. Grosse, Justus Liebigs Ann. Chem., 303, 319 (1898).

15. P. W. Morgan, "Condensation Polymers by Interfacial and Solution Methods," Interscience, New York, N.Y., (1965).

16. Y. Oishi, M. Padmanaban, M. Kakimoto, and Y. Imai, J. Polym. Sci., Polym. Chem. Ed., 25, 3387 (1987).

17. Y. Oishi, M. Kakimoto, and Y. Imai, Macromolecules, 20, 703 (1987).

18. Y. Oishi, M. Kakimoto, and Y. Imai, Macro- molecules, 21, 547 (1988).

19. G. F. L. Ehlers, K. R. Fisch, and W. R. Powell, J. Polym. Sci., A-1, 8, 3511 (1970).

20. H. H. G. Jellinek, "Degradation and Stabilization of Polymers," Vol. 1, Elsevier, Amsterdam, Oxford, New York, 1983.

21. S. Nara and K. Matsuyama, J. Macromol. Sci. Chem., $A, \mathbf{5}, 1205$ (1971).

22. H. A. Scarborough and W. A. Waters, J. Chem. Soc., 130, 89 (1927).

23. R. B. Carlin, R. G. Nelb, and R. C. Odioso, J. Am. Chem. Soc., 73, 1002 (1951).

24. M. Tomita and K. Kimura, J. Pharm. Soc., Jpn., 70, 44 (1950); Chem. Abstr., 44, 4448h (1950). 